\title{
Bile Duct Injuries Indeed Are a Rare, But Much Feared Complication
}

\author{
Aleksandar Resanovic ${ }^{1} \cdot$ Vladimir Resanovic $^{2} \cdot$ Darko Zdravkovic $^{1}$. \\ Borislav Toskovic $^{1} \cdot$ Miroslav Djordjevic $^{1}$
}

Published online: 22 February 2016

(C) Société Internationale de Chirurgie 2016

We read with great care and interest the article on bile duct injuries by Rystedt et al. [1] in the November 2015 issue of World Journal of Surgery. First of all we wish to congratulate the authors on this scientific report and on their dedication to better understanding of this surgical complication.

This was a retrospective study in which the authors wanted to assess the diagnosis, treatment, and outcome of the treatment of bile duct injuries from a national perspective. Bile duct injuries are indeed an unpleasant complication, one that has been scaled down in its incidence drastically over the years. The important thing to point out is the low incidence of bile duct injuries recorded in this paper $(0.3 \%)$, which can only serve as an indication of the high level of training of attending surgeons in all of the hospital centers.

However, we have several concerns regarding the initial operation, the diagnostic procedures, as well as the treatment and follow-up period. We would like to point out that it is unusual for the attending surgeon to perform the reconstructive procedure as well. It has been noted in studies that better results were achieved when the repair after BDI was done by HBP (hepatobiliarypancreatic) surgeon. Also, we think that it would be useful to have noted the severity of BDI generated in cases of acute cholecystitis. [2].

For the diagnostic procedures, we feel that an important factor has been left out, which is liver tissue necrosis in cases with ligation of right hepatic artery. In a paper by Mercado et al. [3], and Schmidt et al. [4], liver injuries

Aleksandar Resanovic

saleresan@gmail.com

1 Klinicko Bolnicki Centar Bezanijska Kosa, Belgrade, Serbia

2 Klinicki Centar Srbije, Belgrade, Serbia were detected and treated in patients that had simultaneous injuries of the common bile duct and the right hepatic artery. Also it has been stated in recent studies that the concomitant vasculobiliary injuries are present in 12-61\% of cases [5].

Regarding the treatment, majority of the patients were treated with direct suture or suture over $\mathrm{T}$ tube. In our experience, the clinical presence of recurrent cholangitis after the period of 3 years of follow-up of BDI repair is not neglectable.

\section{References}

1. Rystedt J, Lindell G, Montgomery A (2015) Bile duct injuries associated with 55,134 cholecystectomies: treatment and outcome from a national perspective. World J Surg. doi:10.1007/s00268015-3281-4

2. Harboe KM, Bardram L (2011) The quality of cholecystectomy in Denmark: outcome and risk factors for 20,307 patients from the national database. Surg Endosc 25:1630-1641

3. Mercado AM, Franssen B, Arriola JC et al (2011) Liver segment IV hypoplasia as a risk factor for bile duct injury. J Gastrointest Surg 15:1589-1593

4. Schmidt SC, Fikatas P, Denecke T et al (2010) Hepatic resection for patients with cholecystectomy related complex bile duct injury. Eur Surg 42(2):77-82

5. Sarno G, Al-Sarira AA, Ghanch P et al (2012) Cholecystectomyrelated bile duct and vasculobiliary injuries. Br J Surg. doi:10. 1002/bjs.8806 